\title{
Trends in cause specific mortality across occupations in Japanese men of working age during period of economic stagnation, 1980-2005: retrospective cohort study

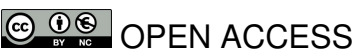

\author{
Koji Wada junior associate professor ${ }^{1}$, Naoki Kondo junior associate professor ${ }^{2}$, Stuart Gilmour \\ assistant professor ${ }^{3}$, Yukinobu Ichida visiting researcher ${ }^{4}$, Yoshihisa Fujino associate professor ${ }^{5}$, \\ Toshihiko Satoh professor ${ }^{6}$, Kenji Shibuya professor ${ }^{3}$
}

${ }^{1}$ Department of Public Health, Kitasato University School of Medicine, 1-15-1 Kitasato Minami-ku Sagamihara, Kanagawa, 252-0374, Japan; ${ }^{2}$ Department of Health Sciences, Interdisciplinary Graduate School of Medicine and Engineering, University of Yamanashi, 1110 Shimokato, Chuo-shi, Yamanashi, 409-3898; ${ }^{3}$ Department of Global Health Policy, University of Tokyo, 7-3-1 Hongo, Bunkyo-ku, Tokyo, 113-0033; ${ }^{4}$ Center for Well-being and Society, Nihon Fukushi University, 5-22-35 Chiyoda, Naka-ku, Nagoya, 460-0012; ${ }^{5}$ Department of Preventive Medicine and Community Health, University of Occupational and Environmental Health, 1-1-1 Iseigaoka, Yahatanishi-ku, Kitakyusyu, Fukuoka, 807-8555; ${ }^{6}$ Kitasato Clinical Research Centre, Kitasato University School of Medicine, 1-15-1 Kitasato Minami-ku Sagamihara, Kanagawa, 252-0374

\begin{abstract}
Objective To assess the temporal trends in occupation specific all causes and cause specific mortality in Japan between 1980 and 2005.

Design Longitudinal analysis of individual death certificates by last occupation before death. Data on population by age and occupation were derived from the population census.

Setting Government records, Japan.

Participants Men aged 30-59.

Main outcome measures Age standardised mortality rate for all causes, all cancers, cerebrovascular disease, ischaemic heart disease, unintentional injuries, and suicide.

Results Age standardised mortality rates for all causes and for the four leading causes of death (cancers, ischaemic heart disease, cerebrovascular disease, and unintentional injuries) steadily decreased from 1980 to 2005 among all occupations except for management and professional workers, for whom rates began to rise in the late 1990s $(P<0.001)$. During the study period, the mortality rate was lowest in other occupations such as production/labour, clerical, and sales workers, although overall variability of the age standardised mortality rate across occupations widened. The rate for suicide rapidly increased since the late 1990s, with the greatest increase being among management and professional workers.
\end{abstract} Conclusions Occupational patterns in cause specific mortality changed
dramatically in Japan during the period of its economic stagnation and
resulted in the reversal of occupational patterns in mortality that have
been well established in western countries. A significant negative effect
on the health of management and professional workers rather than clerks
and blue collar workers could be because of increased job demands
and more stressful work environments and could have eliminated or
even reversed the health inequality across occupations that had existed
previously.
Introduction
During the past half century Japan has achieved considerable
success in population health. ${ }^{1}$ Since 1986, the country has ranked
first internationally in female life expectancy at birth. ${ }^{2}$ A primary
driver of this prolonged life expectancy could be strong
socioeconomic development, the achievement of universal
healthcare coverage, improved diet, and changes in health
behaviour. ${ }^{13}$ Japan's strong economic growth, however, stopped
in the 1990s after its "bubble economy" collapsed, and in 1998,
triggered by the Asian financial crisis and a series of
bankruptcies among big finance firms, Japan experienced the
first negative economic growth in its postwar history. ${ }^{4}$ Over the
past two decades, the Japanese economy has been basically stagnant. The unemployment rate, still lower than that in other 
developed countries, rose from $2.0 \%$ in 1991 to $5.5 \%$ in $2003 .{ }^{5}$ The easing in employment contract regulations in the late 1990s increased the proportion of non-regular workers among male employees from $9 \%$ in 1991 to about $19 \%$ in the late 2000 s. $^{5}$

There is an ongoing debate about Japan's unstable labour market, including concerns about increased unemployment, job insecurity, and widening social disparities and income inequality. ${ }^{6}$ The relatively poorer performance of life expectancy in Japanese men in recent years, compared with women, could be attributable to these rapid changes in the labour market, most remarkably symbolised by the record high male suicide rate since $1998 .{ }^{78}$ We analysed the temporal trends in occupation specific, all cause, and cause specific mortality among Japanese men aged 30-59 in the three decades from 1980 to 2005, when Japan experienced an economic expansion followed by its most serious postwar economic crisis.

\section{Methods \\ Data sources}

We obtained individual death certificates from the occupation specific vital statistics recorded by the Ministry of Health, Labour, and Welfare, Japan from 1980 to $2005 .{ }^{9}$ Every five years, in the same year as the national population census, the government collects information on occupation as well as cause of death from death certificates submitted to the local government by the family of a person who had died..$^{10}$ To calculate occupation specific death rates, we also obtained information on occupation specific populations from the national population census, which is implemented at five year intervals on 1 October. ${ }^{11}$ Following relevant studies, ${ }^{12}{ }^{13}$ we used data only on men because of the poor reliability of the information on occupations for women. In Japan, women are more likely to work on a part time or a non-regular basis (range $44-53 \%$ of total workers in 2007), and $27 \%$ of married women were full time homemakers in $2000 .^{11}$

\section{Measurements}

Data on the death certificate include the underlying cause of death, filled out by physicians and based on the sequence of morbid events leading to death and coded according to ICD-9 (international classification of diseases, ninth revision, 1980-90) and ICD-10 (10th revision, 1995-2005). ${ }^{14}{ }^{15}$ Some codes were inappropriate for analysis of cause of death or were ill defined (such as heart failure) and were redistributed to be comparable and consistent across data by using an algorithm developed by Naghavi and colleagues. ${ }^{16}$ Occupations were classified into 10 categories: professional and engineering (hereinafter professional); management; clerical; sales; services; security services (security); agriculture, forestry, and fisheries (agriculture); transportation and communication (transportation); production and labour work (production/labour); and unemployed. We used the International Standard Classification of Occupations to create these categories. ${ }^{17}{ }^{18}$ In the years when occupation specific vital statistics were undertaken, the family members of dead people were required to select one occupational category from the list of 10 occupations. The list was provided to the family with detailed descriptions and definitions of those categories, as well as job examples for each category (see appendix 1 on mbj.com) and jobs that were not included in the category.

\section{Statistical analysis}

We used data for people aged 30-59. We excluded those aged 20-29, including students in universities and other higher education institutions. We also excluded the population aged 60 and over, which was the typical retirement age in Japan during the study period. With data based on a five year age interval, we computed the age standardised mortality rate, directly adjusted to the 1985 Japan standard population ${ }^{19}$ with the same occupational categorisation as the national census (denominator) and the number of deaths (numerator) for all causes and the five leading causes of death: cancers, ischaemic heart disease, cerebrovascular disease, unintentional injuries, and suicide. We then computed the age standardised mortality rate for the four leading cancers (stomach cancer; larynx, trachea, bronchus, and lung cancer; colorectal cancer; and liver cancer) and categorised occupations into management, professional, the unemployed, and "others" including clerical, sales, services, security, agriculture, transportation, and production/labour on the basis of our analysis of the trend of the age standardised mortality rates.

Data were analysed with a generalised estimating equation model, with an assumed Poisson distribution for the outcome and an exchangeable correlation structure. To model the possible change in mortality in the two specific occupational groups in 2000 , we included a term in all models for management and professional workers. A simple step term was included to reflect the potential change in 2000 across all occupational categories, and an interaction of the step term with management and professional workers was used to identify any additional changes in mortality in these two specific occupations. Time and an interaction between time and management and professional workers were also included in the model, to allow for the possibility of differential changes in death rates over time in these occupational categories. Models were built with backwards stepwise model building.

To evaluate if the variability of age standardised mortality rates across occupations has increased over time, we computed the coefficient of variation of rates. The coefficient of variation is a commonly used normalised measure of variability, defined as the ratio of the standard deviation to the mean. It is suitable for evaluating temporal changes in variability and deals with the possible incomparability of the original standard deviation when its average changes over time.

We analysed the data using Stata version 11 (StataCorp, College Station, TX).

\section{Results}

In the study period, a third of the total male working population were employed in production/labour. The population share of each occupation was mostly stable, although the proportion of professionals increased from $7.4 \%$ to $12.6 \%$. The proportion of management workers decreased from $8.2 \%$ to $3.2 \%$ (table $1 \Downarrow$, and see table $\mathrm{A}$ in appendix 2 on bmj.com for details).

Age standardised mortality rates from all causes and from major conditions declined from 1980 to 2005 , whereas the decline in mortality from cardiovascular diseases stabilised after 1995 (table $2 \Downarrow$ ). The exception was suicide, for which the age standardised mortality rates in 2005 increased by 21.2 per 100 000 compared with 1990. Cancer, the leading cause of death among working age men, showed the largest reduction $(-42 \%)$ followed by mortality from cerebrovascular disease $(-33 \%)$.

Age standardised mortality rates for all causes substantially declined for all occupations and for unemployed people, except 
for management and professional workers. Rates for management and professional workers began to increase in the late 1990s: from 152 in 1995 to 245 in 2000 for management and from 192 in 1995 to 272 in 2000 for professionals (fig $1 \Downarrow$, and see table B in appendix on bmj.com for complete data).

From 1980 to 1995, the all causes age standardised mortality rate largely decreased among sales $(-71 \%)$, clerical $(-66 \%)$, and production/labour workers $(-64 \%)$, while the reductions among other occupations were relatively small ( $-26 \%$ to $-40 \%)$. The age standardised mortality rates for all cancers, ischaemic heart disease, cerebrovascular disease, and unintentional injuries showed mostly similar occupation specific trends to the all causes rate. The rate for suicide, however, did not show a declining trend. In particular, management workers showed the highest increase in the rate for suicide from 1980 to 2005 (271\%), followed by security (138\%) and services (95\%) workers, whereas the rate for suicide among sales, clerical, and production/labour workers did not rise even in the most recent period (after 1995) (see table B in appendix 2 on bmj.com).Table 3 shows the results of the generalised estimating equation model $\Downarrow$. All professions showed a long term downward trend in mortality across the study, though management and professional workers had lower risk of death in the period before 2000. There was, however, evidence of a large change in risk in 2000, with management and professional workers having increased risk of some categories of death (and in all cause mortality) relative to other professions. There was an increase in suicide mortality in 2000 across all occupations but a larger increase among management and professional workers. All workers saw an increase in suicide mortality in 2000 , but this increase was greater among management and professional workers. Increases in the suicide mortality rate among the management and professional workers were similar to those for other illnesses, representing about a $70 \%$ increase in deaths after 2000. Before 2000, however, the management and professional workers experienced significantly lower mortality rates across all six causes of death, with rate ratios of 0.61 to 0.82 (table $4 \Downarrow$ ), all of which were significant. After 2000 this situation was reversed for all cause and all cancer mortality, and the mortality rate for suicide and cerebrovascular disease equalised to those of the non-management and professional workers.

The coefficient of variations of the age standardised mortality rate across occupations, excluding unemployed people, showed an increased trend for all causes and the five leading causes of death (table $5 \Downarrow$ ). The coefficient of variation for the all causes rate across occupations increased from 0.29 in 1980 to 0.46 in 2005. The temporal trend of the coefficient of variation for the suicide rate increased from 0.33 in 1980 to 0.58 in 2005 , while the coefficient of variation for the suicide rate including unemployed people became smaller (table $5^{5}$ ).

Figure $2 \Downarrow$ (and table $\mathrm{C}$ in the appendix on bmj.com) shows the trends in age standardised mortality rates by the four leading sites of cancer. Mortality from stomach cancer showed the largest reduction in this period, whereas rates for lung cancer and colorectal cancer seem to have plateaued. The occupational patterns described for all cancer mortality also seem to be reflected in these cancer specific data series, suggesting that the reversal in declining cancer mortality among management and professional workers occurred across a broad range of cancer sites.

\section{Discussion}

In Japan, trends in mortality varied substantially across occupations and the variability widened from 1980 to 2005, but socioeconomic disparities between occupational groups reduced because of rising mortality among management and professional workers. Many studies in other countries have reported growing health inequality across social classes in from 1980 to $2000 .{ }^{13}$ 20-23 For example, Mackenbach and colleagues reported widening disparities in health between manual and non-manual workers in five European countries between $1981-5$ and $1991-5 .^{24}$ The overall mortality in management and professional workers in Japan, in particular among management, has increased since 2000, whereas that in other workers has showed a steady decline. It should also be noted that, unlike the other four leading causes of death, mortality from suicide showed an upward trend regardless of occupation, along with stagnation in the declining trend in mortality from ischaemic heart disease. As with other causes, management workers showed the poorest performance, with the largest increase in mortality from suicide in later years.

Economists have argued that lingering economic stagnation has been responsible for changes in work environments and employment systems, making the lives of working age people erratic and stressful. ${ }^{6}$ Together with the introduction of ICD-10, this might be one of the potential factors to account for the trend in cardiovascular mortality ceasing to fall after 1995 . This could also explain Japan's counterintuitive trends in occupation specific age standardised mortality rates in recent years. Companies downsized their organisations after the economic recession in the 1990s and consequently the share of managers in the labour market decreased from $6.7 \%$ in 1995 to $3.2 \%$ in 2005. These changes in work environment could increase responsibilities and job demands of managers compared with manufacturing and clerical workers. Yearly working hours for clerical, sales, and production/labour workers decreased from 2162 hours in 1980 to 1970 hours in $2000 .{ }^{25}$ Growing evidence suggests a strong link between job stress and various health outcomes, including metabolic risk factors, mental disorders, and mortality. ${ }^{26}$

Our results are consistent with those from some recent studies that reported that risk factors for cancers and cardiovascular disease - such as being overweight, high alcohol consumption, lower concentrations of high density lipoprotein cholesterol, and physical inactivity - are more prevalent in higher grades of occupations such as professional and management workers in recent years in Japan, potentially because of high job demands among those workers. ${ }^{27-29}$ The authors of these studies have suggested the existence of unique patterns in occupational health gradients in Japan, which could be in part because of strong pressures on high grade workers in Japan, stemming from Japan's particular work culture. ${ }^{30}$ On the other hand, the observed increased gradients in age standardised mortality rates of professionals and managements from 1995 to 2000 might be attributable to the radical changes in socioeconomic conditions of the 1990s rather than to inherent characteristics of Japan's work environment. This observation is, however, contrary to the reduced mortality rates from unintentional injuries and some other causes after the economic crisis. ${ }^{31}$

A possible explanation for the observed increasing trend in mortality for lung cancer and colorectal cancer could be in part because of differences in access to preventive services across occupations. In Japan, under the Industrial Safety and Health Law employers must pay for annual health screening for all employees. In 2004, 73\% of men aged 45-54 had an annual health examination. ${ }^{32}$ Given the increased pressures on management and professional workers, however, their tight daily schedules might prevent them from using the opportunity of health examination and subsequent healthcare benefits, as well as necessary medical care, despite universal health 
coverage. ${ }^{1}$ According to the official cancer registry statistics, the incidence rates of the four cancers analysed here have been stable or declining since $1990 .{ }^{33}$ Therefore, it is unlikely that the observed reversal in trends in mortality from cancer among management and professional workers is because of increased incidence.

Interestingly, we found that variability in suicide rate decreased among all men of working age. When we excluded unemployed men from our analysis, however, the rate increased (table $5 \Downarrow$ ). At the same time, the age standardised mortality rate from suicide increased among workers and not among unemployed people (see table B in appendix on bmj.com). These data support claims that the changing work environment could be primarily responsible for increasing suicide rates in recent years. In a prospective cohort study in Japan, Fujino and colleagues showed that unemployment was not associated with the risk of suicide, ${ }^{34}$ while Granados suggested countercyclical trends of suicide mortality related to Japan's economic fluctuations. ${ }^{35}$ Kondo et al also reported that the percentage of reported poor health among unemployed people was $16.5 \%$ before the economic crisis in 1998 and $12.6 \%$ afterwards. ${ }^{7}$ Because of potential misclassification in this category, these findings require further studies with better data, but the evidence from available studies suggests that unemployment per se is not the driving force behind the changes in mortality patterns observed in this study. An alternative explanation could be that during the study period the unemployment rate doubled, with a relatively higher increase among younger people, and the characteristics of unemployed people could have changed over time, becoming closer to that of general workers in terms of their health risks. ${ }^{36}$

\section{Limitations}

Our study has substantial advantages because of the complete enumeration data used and the application of multiple approaches to standardise the variability in age composition and definitions of cause of death across years. Some caution is nevertheless needed when interpreting our findings, primarily because of potential information bias or misclassifications in occupational categories. Lack of further information, such as employment conditions and company size, prevented us from examining the detailed mechanisms underlying our findings. In addition, numerator-denominator bias attributable to the use of different sources to gather information on the number of deaths and occupations, which can occur if the distribution of populations across occupations are different between the two data sources, ${ }^{37}$ must be considered. For example, the family of a dead person choose his or her last occupation from 10 occupational categories that included unemployment, opening the risk of misclassification bias, especially when, for example, unemployment occurred only shortly before death. To deal with this potential problem, we excluded unemployed people from our primary analysis because misclassification is most likely in this category. ${ }^{12}$ Furthermore, family members might be less likely to report that the person who had died was unemployed if he or she had had a prestigious job before death, potentially resulting in overestimation of mortality rates among such groups. We conducted a sensitivity analysis under the assumption that the entire reduction of professional and management workers of working age represented a shift of these employees into the "other" category, but that dead people continued to be recorded as "professional and management" on death certificates. If we adjust for this effect, the relative risk of death among professional and management workers in 2005 remained higher than it was before $1995(0.99,95 \%$ confidence interval 0.87 to 1.13). Our results, though not as strong, remain unchanged under even the most unrealistic assumptions about the strength of this numerator-denominator bias. Another possible limitation of our research is the model selection method. Our statistical analysis modelled the effect of the recession with a step term estimated from a combination of published work on the point at which increased mortality was observed and empirical observation of the trends in the data. Because of the small number of data points available, we could not test a wider range of model choices without a high risk of spurious statistical results. There were also only six time points, so the findings might be sensitive to boundary effects in the model. A more robust analysis of a wider range of time points might enable a more sensitive comparison of mortality between occupational categories. More time will need to pass before a longer series can be analysed and definitive judgments made about the apparent changes in mortality rates presented here.

\section{Conclusion}

This study has implications for the health effects of the spread of globalisation over the past two decades, which has made global and domestic economies more and more volatile and unstable. In the case of Japan, a major economic collapse in the 1990s, followed by years of economic stagnation and changes in working environment, could have been a factor associated with radical changes in patterns of mortality that had been established since 1980. In addition, certain trends in key causes of mortality were reversed or arrested, and there was a rapid increase in the suicide rate. This emphasises the priority that needs to be placed on suicide prevention among working age men and the importance of reacting quickly to the health consequences of economic collapse. Economic crises might not simply constitute a threat to health equality but can have a complex impact on various subpopulations regardless of their socioeconomic status.

The lessons of Japan's reversal of health outcomes in the 1990s would be particularly relevant given that many similar economies might be beginning to experience the same phenomenon since the 2008 global financial crisis. Policymakers and health professionals should be aware of the pace and magnitude of the impact on population health from a major economic event. The changes experienced in Japan also serve as a reminder that the health gains in modern societies might not necessarily be guaranteed and could be vulnerable to sudden socioeconomic changes.

We thank Zentaro Yamagata (University of Yamanashi) and Keika Hoshi and Guoqin Wang (Kitasato University School of Medicine) for their valuable contributions.

Contributors: $\mathrm{KW}$ and NK conceived and coordinated the project. $\mathrm{KW}$, NK, SG, YI, and YF completed the analysis. KW and NK drafted the initial manuscript. KW, NK, SG, YF, TS, and KS revised the manuscript. All authors commented on drafts of the report. KW and NK contributed equally to the writing of the article and are guarantors.

Funding: This study was funded by the Ministry of Education, Culture, Sports, Science, and Technology (Grant-in-Aid for Scientific Research (B) No 22390130 and Grant-in-Aid for Scientific Research on Innovative Areas No 22119504) and the Ministry of Health, Labour and Welfare (H23-seisaku-shitei-033). The funders had no role in study design, data collection and analysis, and the decision to publish.

Competing interests: All authors have completed the ICMJE uniform disclosure form at www.icmje.org/coi_disclosure.pdf (available on request from the corresponding author) and declare: no support from any organisation for the submitted work; no financial relationships with any organisations that might have an interest in the submitted work in 


\section{What is already known on this topic}

Japanese health is now under threat, especially among men of working age, because of the lingering economic stagnation since the 1990 s, which is characterised by the record high rate of suicide among men

Trends in occupational variations in the mortality rate during the period of Japan's recent economic stagnation are largely unknown

\section{What this study adds}

Risk of mortality in management workers in Japan, which was previously the lowest, largely increased after 1995, whereas in other non-professional workers mortality steadily decreased between 1980 and 2005

During this time mortality from suicide increased in all occupations, with the largest increase among management and professional workers

Economic crises might not simply negatively affect health equality but can have a complex impact on various subpopulations regardless of their socioeconomic status

the previous three years; no other relationships or activities that could appear to have influenced the submitted work.

Ethical approval: Not required

Data sharing: No additional data available.

1 Ikeda N, Saito E, Kondo N, Inoue M, Ikeda S, Satoh T, et al. What has made the population of Japan healthy? Lancet 2011;378:1094-105.

2 World Health Organization. WHO mortality database. 2010. www.who.int/healthinfo/ morttables/en/index.html.

3 Marmot MG, Smith GD. Why are the Japanese living longer? BMJ 1989;299:1547-51.

4 Ito T, Patrick H, Weinstein DE, eds. Reviving Japan's economy: problems and prescriptions. MIT Press, 2005.

5 Statistics Bureau, Ministry of Internal Affairs and Communications. Labor force survey. Ministry of Internal Affairs and Communications, 2010.

6 Tachibanaki T, ed. Confronting income inequality in Japan: a comparative analysis of causes, consequences, and reform. MIT Press, 2005.

7 Kondo N, Subramanian SV, Kawachi I, Takeda Y, Yamagata Z. Economic recession and health inequalities in Japan: analysis with a national sample, 1986-2001. J Epidemiol Community Health 2008;62:869-75.

8 McCurry J. Japan to rethink suicide-prevention policies. Lancet 2008;371:2071.

9 Ministry of Health, Labour and Welfare, Japan. Vital statistics of Japan. 1950-2008. Health and Welfare Statistics Association, 2009.

10 Statistics and Information Department, Minister's Secretariat. Ministry of Health, Labour and Welfare Japan. Vital statitics. 1980-2005. www.mhlw.go.jp/english/database/db-hw/ index.html.

11 Ministry of Internal Affairs and Communications. Population census. 1995-2005. www. stat.go.jp/english/data/kokusei/index.htm.

12 Kunst AE, Groenhof F, Andersen O, Borgan JK, Costa G, Desplanques G, et al. Occupational class and ischemic heart disease mortality in the United States and 11 European countries. Am J Public Health 1999;89:47-53.

13 Harding S. Social class differences in mortality of men: recent evidence from the OPCS longitudinal study. Office of Population Censuses and Surveys. Popul Trends 1995;80:31-7.

14 World Health Organization. Manual of the international statistical classification of diseases, injuries, and causes of death. Ninth revision. WHO, 1977.

15 World Health Organization. International statistical classification of diseases and related health problems. 10th revision. WHO, 1992

16 Naghavi M, Makela S, Foreman K, O'Brien J, Pourmalek F, Lozano R. Algorithms for enhancing public health utility of national causes-of-death data. Popul Health Metr 2010;8:9.

17 Ministry of Internal Affairs and Communications. Japanese standard of occupational classification. 1997. www.stat.go.jp/index/seido/shokgyou/2gaiyou.htm.

18 International Labour Organization. International standard classification of occupations. 2010. www.ilo.org/public/english/bureau/stat/isco/index.htm.

19 Ministry of Internal Affairs and Communications, Japan. Population of Japan 1980-2005. 2006. www.stat.go.jp/English/data/kokusei/index.htm.

20 Blakely T, Tobias M, Atkinson J. Inequalities in mortality during and after restructuring of the New Zealand economy: repeated cohort studies. BMJ 2008:336:371-5.

21 Khang YH, Lynch JW, Yun S, Lee SI. Trends in socioeconomic health inequalities in Korea: use of mortality and morbidity measures. $J$ Epidemiol Community Health 2004;58:308-14.
22 Valkonen T, Martikainen P, Jalovaara M, Koskinen S, Martelin T, Mäkelä P. Changes in socioeconomic inequalities in mortality during an economic boom and recession among middle-aged men and women in Finland. Eur J Public Health 2000;10:274-80.

23 Martikainen $\mathrm{P}$, Valkonen T, Martelin T. Change in male and female life expectancy by social class: decomposition by age and cause of death in Finland 1971-95. J Epidemiol Community Health 2001;55:494.

24 Mackenbach JP, Bos V, Andersen O, Cardano M, Costa G, Harding S, et al. Widening socioeconomic inequalities in mortality in six Western European countries. Int J Epidemiol 2003;32:830-7.

25 Organisation for Economic Co-operation and Development. Employment outlook, 1989-2009. OECD. www.oecd.org/document/0/0,3746,en_2649_33729_40774656_1_1 $11,00 . \mathrm{html}$.

26 Darr W, Johns G. Work strain, health, and absenteeism: a meta-analysis. J Occup Health Psychol 2008;13:293.

27 Takashima Y, Yoshida M, Kokaze A, Orido Y, Tsugane S, Ishikawa M, et al. Relationship of occupation to blood pressure among middle-aged Japanese men--the significance of the differences in body mass index and alcohol consumption. J Epidemiol 1998:8:216-26.

28 Kawakami N, Haratani T, Hemmi T, Araki S. Prevalence and demographic correlates of alcohol-related problems in Japanese employees. Soc Psychiatry Psychiatr Epidemiol 1992;27:198-202.

29 Takao S, Kawakami N, Ohtsu T. Occupational class and physical activity among Japanese employees. Soc Sci Med 2003;57:2281-9.

30 Kagamimori S, Gaina A, Nasermoaddeli A. Socioeconomic status and health in the Japanese population. Soc Sci Med 2009;68:2152-60.

31 Ruhm CJ. Commentary: mortality increases during economic upturns. Int J Epidemiol 2005;34:1206-11

32 Ministry of Health, Labour and Welfare, Japan. Comprehensive survey of living conditions of the people on health and welfare. 2004. www.mhlw.go.jp/toukei/saikin/hw/k-tyosa/ktyosa04/3-7.html.

33 National Cancer Centre, Japan. Cancer statistics in Japan. 2010. http://ganjoho.jp/public statistics/backnumber/2010 en.html.

34 Fujino Y, Mizoue T, Tokui N, Yoshimura T. Prospective cohort study of stress, life satisfaction, self-rated health, insomnia, and suicide death in Japan. Suicide Life Threat Behav 2005;35:227-37.

35 Granados JA. Macroeconomic fluctuations and mortality in postwar Japan. Demography 2008;45:323-43.

36 Ministry of Internal Affairs and Communications, Japan. The survey for labour force in Japan. www.stat.go.jp/english/index.htm.

37 Williams GM, Najman JM, Clavarino A. Correcting for numerator/denominator bias when assessing changing inequalities in occupational class mortality, Australia 1981-2002. Bull World Health Organ 2006;84:198-203.

Accepted: 25 January 2012

Cite this as: BMJ 2012;344:e1191

This is an open-access article distributed under the terms of the Creative Commons Attribution Non-commercial License, which permits use, distribution, and reproduction in any medium, provided the original work is properly cited, the use is non commercial and is otherwise in compliance with the license. See: http://creativecommons.org/licenses/bync/2.0/ and http://creativecommons.org/licenses/by-nc/2.0/legalcode. 


\section{Tables}

Table 1/ Proportion of population by occupation among Japanese men aged 30-59 according to national population census, 1980-2005 (\%) Occupation 1980 (n=24 250 948) 1985 (n=25 896 538) 1990 (n=25 961 345) 1995 (n=26 059 598) 2000 (n=25 935755$) 2005$ (n=25 621 203)

\begin{tabular}{lcccccc} 
Professional & 7.4 & 9.5 & 10.6 & 12.1 & 13.2 & 12.6 \\
\hline Management & 8.2 & 6.3 & 6.6 & 6.7 & 4.1 & 3.2 \\
\hline Others $^{*}$ & 80.3 & 78.9 & 78.4 & 76.0 & 75.7 & 75.9 \\
\hline Unemployed & 4.1 & 5.3 & 4.4 & 5.2 & 7.0 & 8.3 \\
\hline
\end{tabular}

${ }^{*}$ Clerical, sales, services, security, agriculture, transportation, and production/labour. 
Table 2| Number of deaths and age standardised mortality rates per 100000 (95\% confidence intervals) from all causes and five leading causes of death among men aged 30-59 in Japan, 1980-2005

\begin{tabular}{|c|c|c|c|c|c|c|c|c|}
\hline Cause of death & $1980(n=87629)$ & $1985(n=94214)$ & $1990(n=87915)$ & $1995(n=83634)$ & $2000(n=85545)$ & 2005 (80 702) & $\begin{array}{c}* \% \\
\text { change }\end{array}$ & $\begin{array}{l}\text { †Absolute } \\
\text { difference }\end{array}$ \\
\hline All causes & $\begin{array}{c}388.5 \text { (385.9 to } \\
391.1)\end{array}$ & $\begin{array}{c}365.7 \text { (363.4 to } \\
368.0)\end{array}$ & $\begin{array}{c}306.6(304.5 \text { to } \\
308.8)\end{array}$ & $\begin{array}{c}295.7(293.7 \text { to } \\
297.7)\end{array}$ & $\begin{array}{c}293.6(291.6 \text { to } \\
295.6)\end{array}$ & $\begin{array}{c}279.2(277.2 \text { to } \\
281.1)\end{array}$ & -28 & -109 \\
\hline All cancers & $\begin{array}{c}144.5(142.9 \text { to } \\
146.1)\end{array}$ & $\begin{array}{c}121.4(120.1 \text { to } \\
122.8)\end{array}$ & $\begin{array}{c}116.1(114.9 \text { to } \\
117.4)\end{array}$ & $\begin{array}{c}106.9(105.7 \text { to } \\
108.1)\end{array}$ & $\begin{array}{c}100.3(99.1 \text { to } \\
101.4)\end{array}$ & $\begin{array}{c}102.4(101.3 \text { to } \\
103.5)\end{array}$ & -29 & -42 \\
\hline $\begin{array}{l}\text { Ischaemic heart } \\
\text { disease }\end{array}$ & 43.9 (43.0 to 44.8$)$ & 40.4 (39.6 to 41.2$)$ & 38.4 (37.7 to 39.2$)$ & $30.8(30.2$ to 31.5$)$ & 30.5 (29.9 to 31.2$)$ & 32.3 (31.6 to 32.9$)$ & -26 & -12 \\
\hline $\begin{array}{l}\text { Cerebrovascular } \\
\text { disease }\end{array}$ & 57.9 (56.9 to 58.9) & 41.9 (41.1 to 42.7$)$ & 33.8 (33.1 to 34.5 ) & $30.5(29.8$ to 31.1$)$ & 26.8 (26.2 to 27.4$)$ & 25.4 (24.8 to 26.0$)$ & -56 & -33 \\
\hline $\begin{array}{l}\text { Unintentional } \\
\text { injuries }\end{array}$ & 37.3 (36.5 to 38.1$)$ & 34.6 (33.8 to 35.3 ) & 32.2 (31.5 to 32.9$)$ & 31.7 (31.1 to 32.4$)$ & 28.3 (27.6 to 28.9$)$ & 25.7 (25.1 to 26.3 ) & -31 & -12 \\
\hline Suicide & 33.7 (33.0 to 34.5$)$ & $43.2(42.4$ to 44.0$)$ & 30.9 (30.2 to 31.6$)$ & 31.9 (31.1 to 32.5$)$ & $50.3(49.4$ to 51.1$)$ & 53.1 (52.2 to 54.0$)$ & 57 & 19 \\
\hline
\end{tabular}

*Difference between 1980 and 2005 rates expressed as percentage of 1980 rate.

†Absolute difference in age standardised mortality rate per 10000 between 1980 and 2005. 
Table 3| Ratios of age standardised mortality rates for all causes, all cancers, ischaemic heart disease, cerebrovascular disease, unintentional injuries, and suicide mortality: results of generalised estimating equation models for trend analysis

\begin{tabular}{|c|c|c|c|}
\hline Cause of death/variable & Rate ratio & z statistic & $P$ value \\
\hline \multicolumn{4}{|l|}{ All causes } \\
\hline Intercept & 342.85 & 291.73 & $<0.001$ \\
\hline Time & 0.9 & -34.75 & $<0.001$ \\
\hline \multicolumn{4}{|l|}{ Occupation: } \\
\hline Non-management/professional ${ }^{*} v$ management/professional & 0.7 & -7.38 & $<0.001$ \\
\hline \multicolumn{4}{|l|}{ Step function: } \\
\hline $1980-95^{*}$ v 2000-5 & 0.96 & -3.94 & $<0.001$ \\
\hline \multicolumn{4}{|l|}{ Occupation and step: } \\
\hline Non-management/professional after $2000^{*} v$ management/professional after 2000 & 1.69 & 32.71 & $<0.001$ \\
\hline \multicolumn{4}{|l|}{ All cancers } \\
\hline Intercept & 113.42 & 138.58 & $<0.001$ \\
\hline Time & 0.94 & -9.3 & $<0.001$ \\
\hline \multicolumn{4}{|l|}{ Occupation: } \\
\hline Non-management/professional $v$ management/professional & 0.82 & -2.6 & 0.009 \\
\hline \multicolumn{4}{|l|}{ Step function: } \\
\hline $1980-95$ v 2000-5 & 0.76 & -9.67 & $<0.001$ \\
\hline \multicolumn{4}{|l|}{ Occupation and step: } \\
\hline Non-management/professional after $2000^{*} v$ management/professional after 2000 & 1.86 & 17.38 & $<0.001$ \\
\hline \multicolumn{4}{|l|}{ Ischaemic heart disease } \\
\hline Intercept & 39.75 & 62.9 & $<0.001$ \\
\hline Time & 0.88 & -12.61 & $<0.001$ \\
\hline \multicolumn{4}{|l|}{ Occupation: } \\
\hline Non-management/professional ${ }^{\star} v$ management/professional & 0.77 & -1.91 & 0.06 \\
\hline \multicolumn{4}{|l|}{ Step function: } \\
\hline $1980-95^{*}$ v 2000-5 & 0.99 & -0.2 & 0.8 \\
\hline \multicolumn{4}{|l|}{ Occupation and step: } \\
\hline Non-management/professional after $2000^{*} v$ management/professional after 2000 & 1.55 & 8.56 & $<0.001$ \\
\hline \multicolumn{4}{|l|}{ Cerebrovascular disease } \\
\hline Intercept & 49.87 & 75.88 & $<0.001$ \\
\hline Time & 0.8 & -22.13 & $<0.001$ \\
\hline \multicolumn{4}{|l|}{ Occupation: } \\
\hline Non-management/professional ${ }^{*} v$ management/professional & 0.63 & -3.83 & $<0.001$ \\
\hline \multicolumn{4}{|l|}{ Step function: } \\
\hline $1980-95^{*}$ v 2000-5 & 1.03 & 0.91 & 0.4 \\
\hline \multicolumn{4}{|l|}{ Occupation and step: } \\
\hline Non-management/professional after $2000 \mathrm{v}$ management/professional after 2000 & 1.72 & 10.54 & $<0.001$ \\
\hline \multicolumn{4}{|l|}{ Unintentional injury } \\
\hline Intercept & 38.42 & 60.68 & $<0.001$ \\
\hline Time & 0.94 & -8.45 & $<0.001$ \\
\hline \multicolumn{4}{|l|}{ Occupation: } \\
\hline Non-management/professional ${ }^{*} v$ management/professional & 0.54 & -3.71 & $<0.001$ \\
\hline \multicolumn{4}{|l|}{ Step function: } \\
\hline $1980-95^{*}$ v 2000-5 & 0.9 & -3.71 & $<0.001$ \\
\hline \multicolumn{4}{|l|}{ Occupation and step: } \\
\hline Non-management/professional after $2000^{*} v$ nmanagement/professional after 2000 & 1.55 & 9.88 & $<0.001$ \\
\hline \multicolumn{4}{|l|}{ Suicide } \\
\hline Intercept & 32.61 & 55.1 & $<0.001$ \\
\hline Time & 0.97 & -2.32 & 0.02 \\
\hline
\end{tabular}


Table 3 (continued)

Cause of death/variable

Rate ratio $\mathrm{z}$ statistic $\mathrm{P}$ value

Occupation:

\begin{tabular}{llll} 
Non-management/professional ${ }^{*} v$ management/professional & 0.61 & -3.07 & 0.002 \\
\hline Step function: & & & \\
\hline $1980-95^{*} v 2000-5$ & 1.49 & 8.53 & $<0.001$ \\
\hline Occupation and step: & & & \\
\hline Non-management/professional after $2000^{*} v$ management/professional after 2000 & 1.68 & 6.79 & $<0.001$ \\
\hline
\end{tabular}

${ }^{\star}$ Reference category. 
Table 4| Ratios of age standardised mortality rates by cause of death, before 1995 and after 2000, for management/professional versus non-management/professional

\begin{tabular}{lcc} 
Causes of death & Before 1995 & After 2000 \\
All causes & $0.70(0.63 \text { to } 0.76)^{*}$ & $1.18(1.07 \text { to } 1.31)^{*}$ \\
\hline All cancers & $0.82(0.78 \text { to } 0.95)^{\star}$ & $1.52(1.29 \text { to } 1.80)^{*}$ \\
\hline Ischaemic heart disease & $0.77(0.59$ to 1.01$)$ & $1.19(0.89$ to 1.59$)$ \\
\hline Cerebrovascular disease & $0.63(0.50 \text { to } 0.80)^{*}$ & $1.08(0.84$ to 1.40$)$ \\
\hline Unintentional injury & $0.54(0.40 \text { to } 0.75)^{\star}$ & $0.84(0.61$ to 1.18$)$ \\
\hline Suicide & $0.61(0.45 \text { to } 0.84)^{*}$ & $1.03(0.73$ to 1.45$)$ \\
\hline
\end{tabular}

${ }^{*} \mathrm{P}<0.05$ 
Table 5 Trend in variability of mortality rates across occupations. Figures are coefficient of variation ( $95 \%$ confidence interval) of age standardised mortality rate from all causes and five leading causes of death among working men aged 30-59 in Japan, 1980-2005

\begin{tabular}{|c|c|c|c|c|c|c|}
\hline & 1980 & 1985 & 1990 & 1995 & 2000 & 2005 \\
\hline All causes & $0.29(0.14$ to 0.44$)$ & $0.27(0.13$ to 0.42$)$ & $0.34(0.16$ to 0.53$)$ & 0.40 (0.18 to 0.63$)$ & $0.43(0.18$ to 0.67$)$ & $0.46(0.19$ to 0.73$)$ \\
\hline All cancers & 0.21 (0.10 to 0.32$)$ & 0.20 (0.10 to 0.30$)$ & $0.27(0.13$ to 0.40$)$ & 0.35 (0.16 to 0.53$)$ & 0.40 (0.17 to 0.62$)$ & 0.44 (0.19 to 0.69$)$ \\
\hline Ischaemic heart disease & $0.28(0.13$ to 0.42$)$ & $0.29(0.14$ to 0.45$)$ & $0.35(0.16$ to 0.53$)$ & $0.37(0.17$ to 0.58$)$ & 0.40 (0.17 to 0.62$)$ & $0.46(0.19$ to 0.73$)$ \\
\hline Cerebrovascular diseases & $0.35(0.16$ to 0.54$)$ & $0.32(0.15$ to 0.49$)$ & $0.39(0.17$ to 0.61$)$ & $0.44(0.19$ to 0.69$)$ & $0.47(0.19$ to 0.75$)$ & $0.48(0.20$ to 0.77$)$ \\
\hline Suicide & $0.33(0.15$ to 0.51$)$ & $0.36(0.16$ to 0.57$)$ & $0.46(0.19$ to 0.75$)$ & $0.50(0.20$ to 0.81$)$ & $0.56(0.21$ to 0.87$)$ & $0.58(0.21$ to 0.92$)$ \\
\hline \multicolumn{7}{|l|}{ Including unemployed men } \\
\hline All causes & $1.10(0.16$ to 2.03$)$ & 1.05 (0.18 to 1.92$)$ & $1.20(0.11$ to 2.30$)$ & $1.18(0.12$ to 2.25$)$ & $1.07(0.17$ to 1.97$)$ & $1.08(0.17$ to 2.00$)$ \\
\hline All cancers & 0.81 (0.24 to 1.38$)$ & $0.82(0.24$ to 1.39$)$ & $0.96(0.21$ to 1.72$)$ & 0.89 (0.23 to 1.56$)$ & $0.85(0.24$ to 1.47$)$ & $0.94(0.22$ to 1.67$)$ \\
\hline Unintentional injuries & 0.65 (0.24 to 1.06$)$ & 0.59 (0.24 to 0.95$)$ & $0.75(0.24$ to 1.26$)$ & 0.90 (0.23 to 1.58$)$ & $0.79(0.24$ to 1.34$)$ & $0.81(0.24$ to 1.37$)$ \\
\hline Suicide & 1.20 (0.10 to 2.33$)$ & $1.05(0.18$ to 1.94$)$ & $1.22(0.10$ to 2.34$)$ & $1.13(0.13$ to 2.17$)$ & $1.03(0.18$ to 1.94$)$ & $0.93(0.21$ to 1.69$)$ \\
\hline
\end{tabular}




\section{Figures}
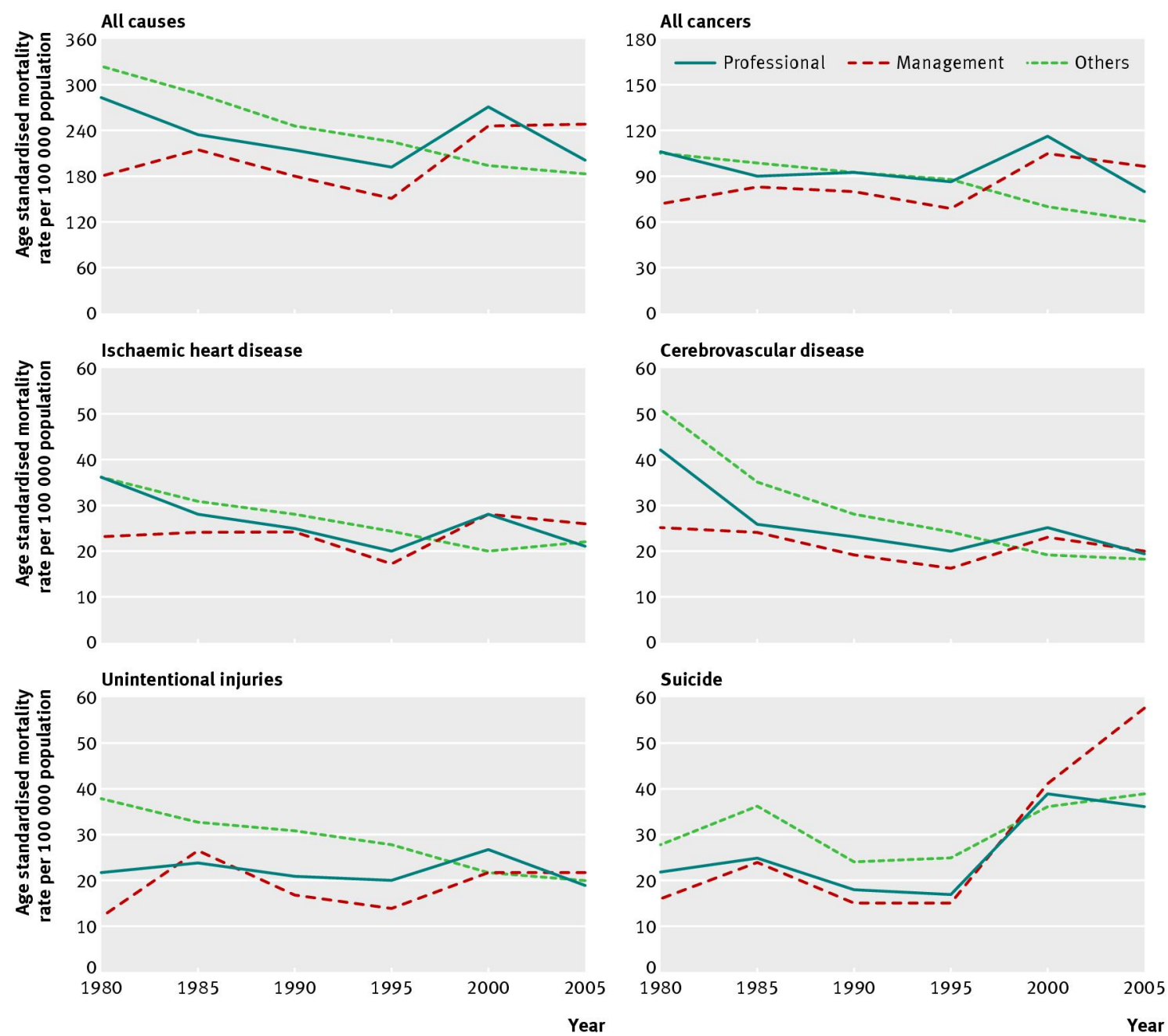

Fig 1 Temporal trends and comparisons of age standardised mortality rates (per 100000 ) from all causes and five leading causes of death, 1980-2005, among men aged 30-59 in Japan 

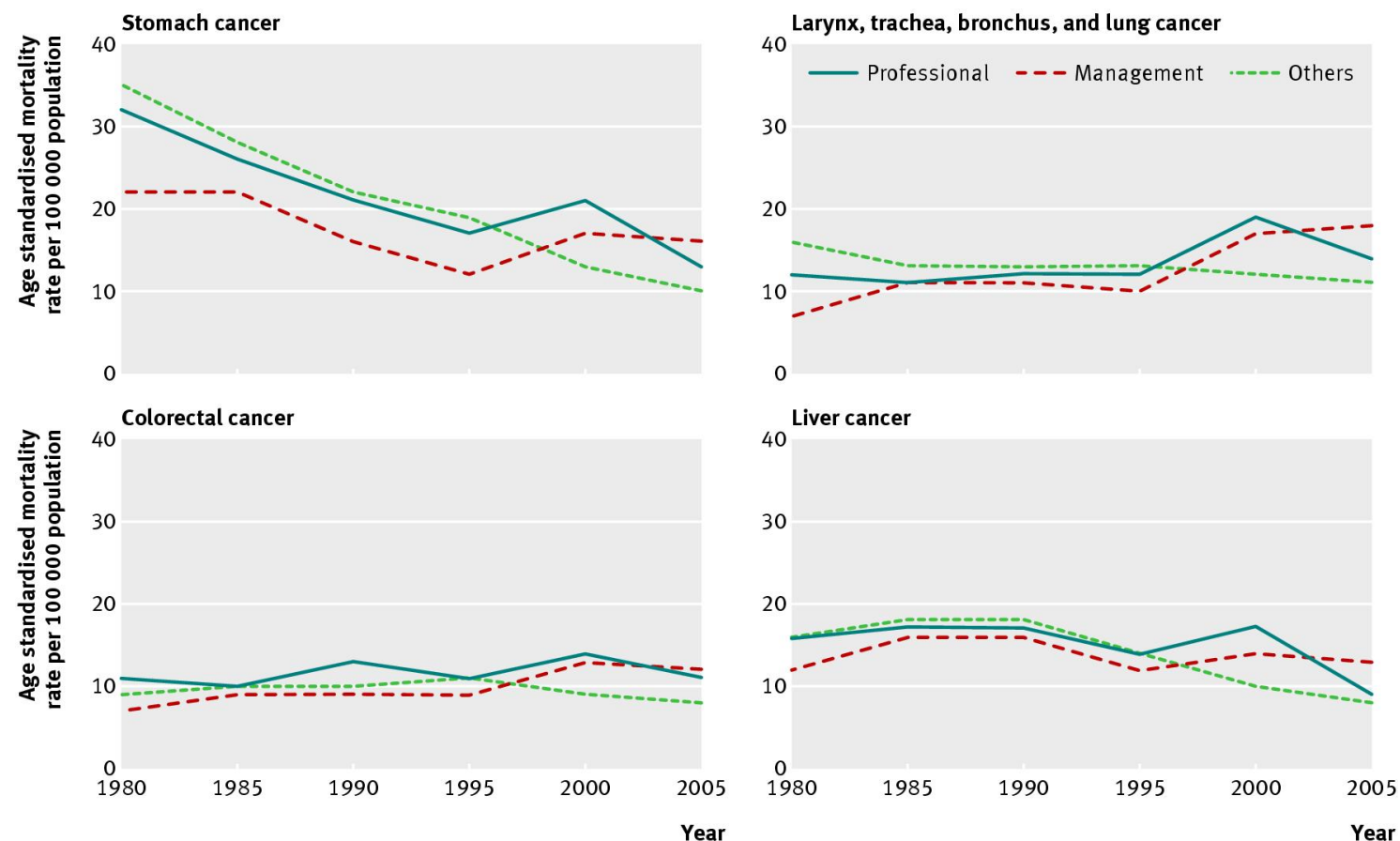

Fig 2 Temporal trends and comparisons of age standardised mortality rates (per 100 000) of four leading cancers, 1980-2005, in men aged 30-59 in Japan 